\title{
Determinação do coeficiente de repetibilidade e estabilização genotípica das características agronômicas avaliadas em genótipos de alfafa no ano de estabelecimento
}

\author{
Reinaldo de Paula Ferreira ${ }^{1}$, Edmar Soares de Vasconcelos ${ }^{2}$, Cosme Damião Cruz ${ }^{3}$, Waldomiro Barioni Júnior ${ }^{4}$, \\ Joaquim Bartolomeu Rassini ${ }^{5}$, Alfredo Ribeiro de Freitas ${ }^{5}$, Duarte Vilela ${ }^{6}$, Adônis Moreira ${ }^{1}$
}

\begin{abstract}
RESUMO
Foram estimados os coeficientes de repetibilidade das características de produção de matéria seca (PMS), altura das plantas no momento do corte (APC), tolerância a doenças (TD) e altura no florescimento (AF), em genótipos de alfafa. As características foram avaliadas em 92 genótipos nos anos 2004 e 2005, durante 11 cortes, feitos nos períodos das águas (novembro a março, cinco cortes) e da seca (abril a setembro, seis cortes). O experimento foi conduzido em blocos ao acaso, com duas repetições. As estimativas dos coeficientes de repetibilidade foram obtidas por diferentes métodos de análises. Também realizou-se estudo da estabilização genotípica. Todas as análises estatísticas foram realizadas com auxílio do aplicativo computacional GENES. No período da seca, apenas dois cortes foram suficientes para se ter certeza de 85\% na previsão do valor real para a PMS, sendo necessários cinco cortes para se obter a mesma confiabilidade nesta característica no período das águas. De maneira geral, no período das águas foi necessário maior número de avaliações para obter igual veracidade da comprovação genotípica. Pela estabilização genotípica, observouse aumento da confiabilidade com a eliminação de alguns cortes, chegando a até $97 \%$ com apenas três cortes, excluindose dois cortes iniciais e um final. As variáveis PMS e APC, no período das águas, apresentaram maiores estimativas do coeficiente de repetibilidade do que TD e AF.
\end{abstract}

Palavras-chave: Características agronômicas, estabilização genotípica, Medicago sativa L., período das águas, período da seca, repetibilidade.

\section{ABSTRACT}

\section{Determination of genotype stabilization and repeatability coefficient for agronomic traits in alfalfa genotypes in the establishment year}

Repeatibility coefficients were estimated for dry matter production (DMP), plant height at cutting time (PHC), disease tolerance (DT) and height at flowering (HF). The characteristics were evaluated in 92 genotypes in the years 2004 and 2005. Five cuttings were carried out in the rain period (November to March) and six cuttings in the dry period (April to September). The experiment was arranged in randomized block design, with two replications. The estimates of the repeatability coefficient were obtained by different methods and, then, the study of genotype stabilization was performed. The statistical analyses were done using the GENES software. During the dry period, only two cuttings

Recebido para publicação em março de 2007 e aprovado em junho de 2010

${ }^{1}$ Engenheiros-Agrônomos, Doutores. Pesquisadores da Embrapa Pecuária Sudeste, 13560-570, São Carlos, São Paulo, Brasil. reinaldo@cppse.embrapa.br

2 Engenheiro-Agrônomo, Mestre. Doutorando em Genética e Melhoramento de Plantas, Universidade Federal de Viçosa, 36570-000, Viçosa, Minas Gerais, Brasil. vasconceloses@vicosa.ufv.br

${ }^{3}$ Engenheiro-Agrônomo, Doutor. Departamento de Biologia Geral, Universidade Federal de Viçosa, 36570-000, Viçosa, Minas Gerais, Brasil. cdcruz@ufv.br

${ }^{4}$ Estatístico, Mestre. Pesquisador da Embrapa Pecuária Sudeste, São Carlos, São Paulo, Brasil. barioni@cppse.embrapa.br

${ }^{5}$ Engenheiros-Agrônomos, Doutores. Pesquisadores aposentados da Embrapa Pecuária Sudeste, 13560-570, São Carlos, São Paulo, Brasil.

Engenheiro-Agrônomo, Doutor. Pesquisador da Embrapa Gado de Leite, 36038-330, Juiz de Fora, Minas Gerais, Brasil. vilela@cnpgl.embrapa.br 
were enough to achieve $85 \%$ accuracy in the estimation of the real DMP value, whereas in the rain period, five cuttings were required to achieve the same reliability. Overall, in the rain period a larger number of evaluations was required to obtain the same data reliability. For genotype stabilization, there was increase in reliability by leaving out some cuttings. The variables DMP and PHC, during the rain period, showed larger estimates for the repeatability coefficient than the variables DT and HF.

Key words: Agronomic traits, genotype’s stabilization, Medicago sativa L., repeatability, rain period, dry period.

\section{INTRODUÇÃO}

Com a intensificação da produção de leite, visando obter maior produtividade e menores custos, é essencial suplementação de qualidade. $\mathrm{O}$ uso da alfafa como alternativa alimentar para o rebanho leiteiro vem crescendo, pois esta é uma das plantas forrageiras de maior produtividade, qualidade e aceitabilidade pelos animais, propiciando bons resultados na produção de leite (Vilela, 1994).

Os estudos de melhoramento de alfafa no Brasil ainda são incipientes, e a introdução de materiais do exterior vem sendo a principal estratégia para a disponibilização desse germoplasma aos programas de melhoramento (Ferreira \& Pereira, 2005). Na experimentação com espécies forrageiras é comum a comparação da superioridade fenotípica de cultivares por meio de avaliação em cortes sucessivos. Contudo, não há informações precisas sobre o número adequado de medições que devem ser realizadas nos experimentos para a obtenção de estimativas confiáveis, com um custo mínimo e menor emprego de mão de obra.

Dentre as características agronômicas importantes para o melhoramento de forrageiras, a produtividade de matéria seca se destaca e tem sido avaliada na maioria dos ensaios comparativos de desempenho de cultivares de alfafa (Julier et al., 2000; Botrel et al., 2001; Guines et al., 2002; Katepa-Mupondwa et al., 2002). O potencial de produção de matéria seca de alfafa é em torno de 25 t/ha/ano, não sendo, muitas vezes, obtido por limitações edafoclimáticas (Fontes et al., 1993).

A produtividade é o resultado final de diversas outras características, como resistência a pragas e doenças, tolerância aos diversos tipos de estresses abióticos, podendo ser utilizada como característica representativa da adaptação dos diferentes materiais genéticos. Esse fato torna-se importante por facilitar a avaliação dos ensaios, pelo menor número de características avaliadas e por reduzir o custo final dos trabalhos de melhoramento.

Os resultados da avaliação de características agronômicas obtidas em cortes sucessivos tem sido, comumente, utilizados na comparação da superioridade fenotípica de cultivares de espécies forrageiras. Contudo, uma das dificuldades encontradas para o melhoramento dessas espé- cies é a determinação do número de avaliações necessárias para se estimar a diferença entre os materiais avaliados, de tal forma que ao se escolher determinado genótipo espera-se que sua superioridade perdure por maior período de tempo. Essa expectativa poderá ser comprovada pelo coeficiente de repetibilidade da característica estudada, sendo ele passível de estimação quando a medição do caráter for realizada repetidas vezes em determinado indivíduo (Cruz et al., 2004).

As várias medidas em uma mesma planta podem ser efetuadas ao longo do tempo ou dentro de diferentes partes ou órgãos do indivíduo. Havendo disponibilidade dessas medidas, é possível estimar coeficientes de repetibilidade que propiciem quantificar o número de medições necessárias para se obter uma predição do valor real do indivíduo (Cruz et al., 2004).

A repetibilidade estima o valor máximo que a herdabilidade pode atingir, pois expressa a proporção da variância fenotípica que é atribuída às diferenças genéticas confundidas com os efeitos permanentes que atuam na variedade ou progênie. Assim, sob certas pressuposições, a repetibilidade, à semelhança da herdabilidade, constitui ferramenta indispensável para auxiliar o processo de seleção realizado pelo melhorista.

O objetivo deste trabalho foi estimar os coeficientes de repetibilidade para as características de produção de matéria seca (PMS), altura de plantas no momento do corte (APC), tolerância a doenças (TD) e altura no florescimento (AF), em genótipos de alfafa.

\section{MATERIAL E MÉTODOS}

O experimento foi conduzido na Embrapa Pecuária Sudeste, São Carlos, São Paulo, tendo início em junho de 2004, em um Latossolo Vermelho-Amarelo. No preparo do solo aplicaram-se 5,0 t/ha de calcário dolomítico (maio/ 2004), seguido de adubação no estabelecimento da cultura, com a aplicação de $80 \mathrm{~kg} / \mathrm{ha}$ de superfosfato simples, $100 \mathrm{~kg} / \mathrm{ha}$ de cloreto de potássio e $30 \mathrm{~kg} / \mathrm{ha}$ de FTE-BR12. Em junho/2004 foi feita a semeadura de 92 acessos de alfafa provenientes do INTA-Argentina, tendo como testemunha o cultivar Crioula, advindo de sementes da Embrapa Gado de Leite, Coronel Pacheco, Minas Gerais. 
Foram utilizados $20 \mathrm{~kg}$ de sementes viáveis/ha, previamente inoculadas com estirpes de Rhizobium melilotti e espaçamento de $20 \mathrm{~cm}$ entre linhas. Para a adubação de cobertura aplicaram-se a lanço, após cada corte, $60 \mathrm{~kg} / \mathrm{ha}$ de $\mathrm{K}_{2} \mathrm{O}$, na forma de cloreto de potássio. O delineamento experimental foi o de blocos ao acaso, com duas repetições, sendo as parcelas constituídas de cinco fileiras de cinco metros de comprimento. Considerou-se como bordadura uma fileira de plantas em cada lado e 0,50 m de cada extremidade da parcela. Os cortes de avaliação da alfafa foram realizados quando a maioria dos materiais apresentava $10 \%$ de plantas em florescimento. Os tratos culturais foram realizados sempre que necessário e de acordo com as recomendações para o cultivo da alfafa (Ferreira et al., 2008).

As características avaliadas foram: produção de matéria seca (PMS), sendo os cortes realizados quando grande parte dos genótipos apresentava $10 \%$ de plantas em florescimento; altura da planta no momento de corte (APC), quantificada por meio da média de cinco plantas por parcela e em cm; aceitação fenotípica (AFe), que dá uma ideia do comportamento geral do cultivar (atribuindo-se notas como segue: 1 - excelente; 2 - ótimo; 3 - bom; 4 - regular; 5 - ruim); tolerância a doenças (TD) (atribuindo-se notas como segue: 0 - susceptível; 1 - baixa resistência; 2 - moderadamente resistente; 3 - altamente resistente). No presente trabalho analisaram-se as características de produção de matéria seca nos períodos das águas (PMSA) e da seca (PMSS); altura das plantas no momento do corte nos períodos das águas (APCA) e da seca (APCS); tolerância a doenças nos períodos das águas (TDA) e da seca (TDS); e altura no florescimento nos períodos das águas (AFA) e da seca (AFS).

Definiu-se como período de avaliação duas épocas (águas: novembro a março do ano de 2004/2005; seca: abril a setembro do ano de 2005), realizando cinco cortes na época das águas e seis na época da seca. As análises foram realizadas sobre as médias dos dados das características analisadas, e os métodos empregados para estimação do coeficiente de repetibilidade foram: análise de variância, na qual o efeito temporário de ambiente é removido do erro; componentes principais obtidos da matriz de correlação; componentes principais obtidos da matriz de covariâncias; e análise estrutural com base no autovalor teórico da matriz de correlações ou correlação média.

As análises estatísticas foram realizadas com o auxílio do aplicativo computacional GENES (Cruz, 2006).

\section{RESULTADOS E DISCUSSÃO}

Os dados obtidos para as variáveis produção de matéria seca, altura da planta no momento do corte e tolerância a doenças seguiram a distribuição normal, porém foi necessária a transformação dos dados de altura de planta na floração (AF) para raiz quadrada de AF, obtendo-se, assim, a normalidade dos dados. Todas as características apresentaram homogeneidade de variância, o que permitiu a análise de variância conjunta.
Pelos resultados obtidos com a análise de repetibilidade, observa-se que na época da seca as estimativas dos coeficientes de repetibilidade, sem a estabilização genotípica, foram superiores às obtidas no período das águas para todas as características avaliadas (Tabelas 1 e 2). Para a variável produção de matéria seca, verificou-se variação de 0,7425 a 0,7988 nas estimativas do coeficiente de repetibilidade. Essa baixa amplitude de variação demonstra a eficiência dos métodos empregados na estimação do coeficiente de repetibilidade. As variações nas estimativas desse coeficiente, proporcionadas pelos diferentes métodos, foram pequenas.

A variável altura de plantas no momento do corte foi a que apresentou os maiores valores do coeficiente de repetibilidade, chegando a valores próximos de 90\%, enquanto a variável tolerância a doenças apresentou os menores índices para esse coeficiente, atingindo um mínimo de 55\%.

Os valores de repetibilidade, próximos a 75\%, indicam a necessidade de menor número de repetições para a obtenção de maior precisão no experimento (isso se dá pela menor variação ambiental verificada nas avaliações), uma vez que para atingir $85 \%$ de precisão para a PMSS (em que o coeficiente de repetibilidade foi próximo de 0,75 ) foi necessária a avaliação de apenas dois cortes. No período das águas, para a mesma variável seria necessário avaliar cinco cortes para a obtenção da mesma precisão, pois a estimativa do coeficiente de repetibilidade variou de 0,5617 a 0,6107, valores menores que os estimados para PMSS. Isso é consequência da variância ambiental; quanto maior essa for menor será o coeficiente de repetibilidade, exigindo maior número de cortes para se chegar à mesma precisão experimental.

Os valores de repetibilidade influenciaram nas estimativas do número de indivíduos necessário para a obtenção de um dado valor do coeficiente de determinação (Tabela 3). Quanto maior o valor da estimativa do coeficiente de repetibilidade menor o número de repetições para se obter um dado valor do coeficiente de determinação.

Os seis cortes realizados na época da seca proporcionaram precisão acima de $90 \%$ para as características PMSS, APCS e AFS, enquanto para a variável TDS obteve-se uma precisão entre 85 e 90\% (Tabela 3). Com cinco cortes na época das águas (Tabela 4), foi obtida uma certeza experimental próxima de $90 \%$ apenas para a variável APCA.

Pelos resultados, verifica-se que o número de repetições para a característica PMS utilizado neste experimento foi adequado, gerando confiabilidade acima de $90 \%$, mesmo sem realizar a estabilização genotípica. Resultados semelhantes foram obtidos para a característica APC tanto no período da seca quanto no das águas.

Com relação às variáveis TD e AF, seria necessário um maior número de repetições que o utilizado, uma vez que a confiabilidade dos resultados foi inferior a 80\% (Tabela 5).

Ao se realizar a estabilização genotípica dos materiais pelo método dos componentes principais utilizando matriz 
de correlação, obteve-se confiabilidade dos resultados com apenas a metade das avaliações realizadas, isso para as variáveis PMSS e APCS; ou seja, houve 50\% de economia nos custos ao se trabalhar apenas com os cortes de junho, julho e agosto, 3, 4 e 5, respectivamente, porém mantendo a mesma precisão experimental. Para a variável TDS, a exclusão dos cortes de abril (1), agosto (5) e setembro (6) não altera a confiabilidade dos resultados. Para a variável AFS

Tabela 1. Estimativas de repetibilidade ( $r$ e do coeficiente de determinação genotípico $\left(\mathrm{R}^{2}\right)$ obtidas da análise da PMSS, APCS, TDS e AFS avaliadas em cultivares de alfafa na época da seca do ano de 2005, baseadas em diferentes métodos

\begin{tabular}{|c|c|c|c|c|c|c|c|c|}
\hline \multirow{2}{*}{ Métodos } & \multicolumn{2}{|c|}{ PMSS $^{1}$} & \multicolumn{2}{|c|}{$\mathbf{A P C S}^{2}$} & \multicolumn{2}{|c|}{ TDS $^{3}$} & \multicolumn{2}{|c|}{ AFS $^{4}$} \\
\hline & $\mathbf{r}$ & $\mathbf{R}^{2}$ & $\mathbf{r}$ & $\mathbf{R}^{2}$ & $\mathbf{r}$ & $\mathbf{R}^{2}$ & $\mathbf{r}$ & $\mathbf{R}^{2}$ \\
\hline ANOVA $^{5}$ & 0,7425 & 94,5359 & 0,8544 & 97,2388 & 0,5519 & 88,0815 & 0,7193 & 93,8931 \\
\hline $\mathrm{CP}(\mathrm{cov})^{6}$ & 0,7988 & 95,9718 & 0,9056 & 98,2927 & 0,6134 & 90,4951 & 0,7290 & 94,1645 \\
\hline $\mathrm{CP}(\text { correl })^{7}$ & 0,7641 & 95,1075 & 0,8925 & 98,0321 & 0,5641 & 88,5891 & 0,7286 & 94,1544 \\
\hline $\mathrm{AE}(\mathrm{cov})^{8}$ & 0,7575 & 94,9336 & 0,8923 & 98,0279 & 0,5606 & 88,4442 & 0,7276 & 94,1264 \\
\hline
\end{tabular}

${ }^{1}$ Produção de matéria seca no período da seca; ${ }^{2}$ Altura da planta no momento do corte no período da seca; ${ }^{3}$ Tolerância a doenças no período da seca; ${ }^{4}$ Altura de plantas no florescimento no período da seca; ${ }^{5}$ Análise de variância na qual o efeito temporário de ambiente é removido do erro; ${ }^{6}$ Componentes principais obtidos da matriz de correlação; ${ }^{7}$ Componentes principais obtidos da matriz de covariâncias; e ${ }^{8}$ Análise estrutural com base no autovalor teórico da matriz de correlações ou correlação média.

Tabela 2. Estimativas de repetibilidade ( $r$ e do coeficiente de determinação genotípico $\left(\mathrm{R}^{2}\right)$ obtidas da análise da PMSA, APCA, TDA e AFA avaliadas em cultivares de alfafa na época das águas no ano de 2004/2005, baseadas em diferentes metodologias

\begin{tabular}{|c|c|c|c|c|c|c|c|c|}
\hline \multirow{2}{*}{ Métodos } & \multicolumn{2}{|c|}{ PMSA $^{1}$} & \multicolumn{2}{|c|}{ APCA $^{2}$} & \multicolumn{2}{|c|}{ TDA $^{3}$} & \multicolumn{2}{|c|}{ AFA $^{4}$} \\
\hline & $\mathbf{r}$ & $\mathbf{R}^{2}$ & $\mathbf{r}$ & $\mathbf{R}^{2}$ & $\mathbf{r}$ & $\mathbf{R}^{2}$ & $\mathbf{r}$ & $\mathbf{R}^{2}$ \\
\hline $\mathrm{ANOVA}^{5}$ & 0,5617 & 86,5003 & 0,6820 & 91,4699 & 0,2522 & 62,7740 & 0,1753 & 51,5209 \\
\hline $\mathrm{CP}(\mathrm{cov})^{6}$ & 0,6104 & 88,6777 & 0,7319 & 93,1752 & 0,3295 & 71,0762 & 0,4115 & 77,7562 \\
\hline $\mathrm{CP}(\text { correl })^{7}$ & 0,6107 & 88,6931 & 0,6878 & 91,6793 & 0,2660 & 64,4351 & 0,3616 & 73,9016 \\
\hline $\mathrm{AE}(\mathrm{cov})^{8}$ & 0,6083 & 88,5925 & 0,6737 & 91,1683 & 0,2390 & 61,0950 & 0,1619 & 49,1388 \\
\hline
\end{tabular}

${ }^{1}$ Produção de matéria seca no período das águas; ${ }^{2}$ Altura da planta no momento do corte no período das águas; ${ }^{3}$ Tolerância a doenças no período das águas; ${ }^{4}$ Altura de plantas no florescimento no período das águas; ${ }^{5}$ Análise de variância na qual o efeito temporário de ambiente é removido do erro; ${ }^{6}$ Componentes principais obtidos da matriz de correlação; ${ }^{7}$ Componentes principais obtidos da matriz de covariâncias; e ${ }^{8}$ Análise estrutural com base no autovalor teórico da matriz de correlações ou correlação média.

Tabela 3. Estimativa do número de medições necessárias para a obtenção de diferentes valores do coeficiente de determinação, obtidos para o período da seca do ano de 2005

\begin{tabular}{|c|c|c|c|c|c|c|c|c|c|c|c|c|}
\hline \multirow{2}{*}{ Métodos } & \multicolumn{3}{|c|}{ PMSS $^{1}$} & \multicolumn{3}{|c|}{ APCS $^{2}$} & \multicolumn{3}{|c|}{ TDS $^{3}$} & \multicolumn{3}{|c|}{ AFS $^{4}$} \\
\hline & 0,90 & 0,95 & 0,99 & 0,90 & 0,95 & 0,99 & 0,90 & 0,95 & 0,99 & 0,90 & 0,95 & 0,99 \\
\hline ANOVA $^{5}$ & 3,12 & 6,59 & 34,33 & 1,53 & 3,24 & 16,87 & 7,31 & 15,43 & 80,38 & 3,51 & 7,42 & 38,63 \\
\hline $\mathrm{CP}(\mathrm{cov})^{6}$ & 2,27 & 4,79 & 24,93 & 0,94 & 1,98 & 10,32 & 5,67 & 11,97 & 62,39 & 3,35 & 7,07 & 36,81 \\
\hline $\mathrm{CP}$ (correl) $)^{7}$ & 2,78 & 5,86 & 30,56 & 1,08 & 2,29 & 11,92 & 6,96 & 14,68 & 76,51 & 3,53 & 7,08 & 36,88 \\
\hline $\mathrm{AE}(\mathrm{cov})^{8}$ & 2,88 & 6,08 & 31,70 & 1,09 & 2,29 & 11,95 & 7,06 & 14,90 & 77,61 & 3,37 & 7,11 & 37,07 \\
\hline
\end{tabular}

${ }^{1}$ Produção de matéria seca no período da seca; ${ }^{2}$ Altura da planta no momento do corte no período da seca; ${ }^{3}$ Tolerância a doenças no período da seca; ${ }^{4}$ Altura de plantas no florescimento no período da seca; ${ }^{5}$ Análise de variância na qual o efeito temporário de ambiente é removido do erro; ${ }^{6}$ Componentes principais obtidos da matriz de correlação; ${ }^{7}$ Componentes principais obtidos da matriz de covariâncias; e ${ }^{8}$ Análise estrutural com base no autovalor teórico da matriz de correlações ou correlação média.

Tabela 4. Estimativa do número de medições necessárias para a obtenção de diferentes valores do coeficiente de determinação, obtidos para o período das águas do ano de 2004/2005 para PMS e APC

\begin{tabular}{|c|c|c|c|c|c|c|c|c|}
\hline \multirow{2}{*}{ Métodos } & \multicolumn{4}{|c|}{ PMSA $^{1}$} & \multicolumn{4}{|c|}{ APCA $^{2}$} \\
\hline & 0,80 & 0,90 & 0,95 & 0,99 & 0,80 & 0,90 & 0,95 & 0,99 \\
\hline $\mathrm{ANOVA}^{3}$ & 3,12 & 7,02 & 14,83 & 77,25 & 1,87 & 4,20 & 8,86 & 46,16 \\
\hline $\mathrm{CP}(\mathrm{cov})^{4}$ & 2,55 & 5,75 & 12,13 & 63,20 & 1,47 & 3,30 & 6,96 & 36,26 \\
\hline $\mathrm{CP}(\text { correl })^{5}$ & 2,55 & 5,74 & 12,11 & 63,10 & 1,82 & 4,08 & 8,63 & 44,94 \\
\hline $\mathrm{AE}(\mathrm{cov})^{6}$ & 2,58 & 5,79 & 12,23 & 63,74 & 1,94 & 4,36 & 9,20 & 47,95 \\
\hline
\end{tabular}

${ }^{1}$ Produção de matéria seca no período das águas; ${ }^{2}$ Altura da planta no momento do corte no período das águas; ${ }^{3}$ Análise de variância na qual o efeito temporário de ambiente é removido do erro; ${ }^{4}$ Componentes principais obtidos da matriz de correlação; ${ }^{5}$ Componentes principais obtidos da matriz de covariâncias; e ${ }^{6}$ Análise estrutural com base no autovalor teórico da matriz de correlações ou correlação média. 
(Tabela 6), trabalhando apenas com os cortes 4 e 5, não se tem alteração na veracidade dos resultados.

Para as análises do período das águas, trabalhar com os cortes de fevereiro (4) e março (5) proporciona aumento em torno de $5 \%$ na confiabilidade dos resultados das variáveis PMSA, APCA e TDA. Para a variável AFA, trabalhar com os cortes de janeiro (3) e fevereiro (4) aumenta a confiabilidade do experimento de 51 para 78\% (Tabela 7).

Tabela 5. Estimativa do número de medições necessárias para a obtenção de diferentes valores do coeficiente de determinação obtidos para o período das águas do ano de 2005, para TD e AF

\begin{tabular}{|c|c|c|c|c|c|c|c|c|}
\hline \multirow{2}{*}{ Métodos } & \multicolumn{4}{|c|}{ TDA $^{1}$} & \multicolumn{4}{|c|}{$\mathbf{A F A}^{2}$} \\
\hline & 0,80 & 0,90 & 0,95 & 0,99 & 0,80 & 0,90 & 0,95 & 0,99 \\
\hline ANOVA $^{3}$ & 11,86 & 26,69 & 56,34 & 293,54 & 18,82 & 42,34 & 89,39 & 465,78 \\
\hline $\mathrm{CP}(\mathrm{cov})^{4}$ & 8,14 & 18,31 & 38,66 & 201,44 & 5,72 & 12,87 & 27,18 & 141,61 \\
\hline $\mathrm{CP}(\text { correl })^{5}$ & 11,04 & 24,84 & 52,44 & 273,22 & 7,06 & 15,89 & 33,55 & 174,81 \\
\hline $\mathrm{AE}(\operatorname{cov})^{6}$ & 12,74 & 28,66 & 60,50 & 315,21 & 20,70 & 46,58 & 98,33 & 512,35 \\
\hline
\end{tabular}

${ }^{1}$ Tolerância a doenças no período das águas; ${ }^{2}$ Altura de plantas no florescimento no período das águas; ${ }^{3}$ Análise de variância na qual o efeito temporário de ambiente é removido do erro; ${ }^{4}$ Componentes principais obtidos da matriz de correlação; ${ }^{5}$ Componentes principais obtidos da matriz de covariâncias; e ${ }^{6}$ Análise estrutural com base no autovalor teórico da matriz de correlações ou correlação média.

Tabela 6. Estabilização genotípica de experimentos de alfafa, realizados no período da seca do ano de 2005

\begin{tabular}{|c|c|c|c|c|c|c|c|c|}
\hline \multirow[t]{2}{*}{ Avaliações $^{7}$} & \multicolumn{2}{|c|}{ PMSS $^{1}$} & \multicolumn{2}{|c|}{$\mathbf{A P C S}^{2}$} & \multicolumn{2}{|c|}{ TDS $^{3}$} & \multicolumn{2}{|c|}{$\mathbf{A F S}^{4}$} \\
\hline & Rep. $^{5}$ & Det. $(\%)^{6}$ & Rep. $^{5}$ & Det. $(\%)^{6}$ & Rep. $^{5}$ & Det. $(\%)^{6}$ & Rep. $^{5}$ & Det. $(\%)^{6}$ \\
\hline $1-2$ & 0,86 & 92,26 & 0,88 & 93,83 & 0,61 & 76,09 & 0,78 & 87,52 \\
\hline $2-3$ & 0,86 & 92,25 & 0,88 & 93,66 & 0,74 & 84,91 & 0,70 & 82,47 \\
\hline $3-4$ & 0,87 & 93,32 & 0,95 & 97,32 & 0,66 & 79,65 & 0,65 & 78,48 \\
\hline $4-5$ & 0,91 & 95,42 & 0,95 & 97,35 & 0,62 & 76,41 & 0,88 & 93,51 \\
\hline $5-6$ & 0,66 & 79,26 & 0,88 & 93,79 & 0,54 & 69,72 & 0,76 & 86,60 \\
\hline $1-3$ & 0,84 & 94,00 & 0,88 & 95,80 & 0,65 & 84,63 & 0,71 & 88,19 \\
\hline $2-4$ & 0,86 & 94,90 & 0,90 & 96,55 & 0,68 & 86,48 & 0,71 & 87,92 \\
\hline $3-5$ & 0,89 & 95,87 & 0,94 & 97,98 & 0,61 & 82,59 & 0,73 & 89,00 \\
\hline $4-6$ & 0,72 & 88,28 & 0,90 & 96,52 & 0,58 & 80,41 & 0,80 & 92,36 \\
\hline $1-4$ & 0,83 & 95,03 & 0,89 & 97,07 & 0,63 & 87,10 & 0,71 & 90,92 \\
\hline $2-5$ & 0,87 & 96,53 & 0,92 & 97,74 & 0,62 & 86,65 & 0,73 & 91,65 \\
\hline $3-6$ & 0,75 & 92,25 & 0,91 & 97,54 & 0,59 & 85,05 & 0,73 & 91,60 \\
\hline $1-5$ & 0,84 & 96,30 & 0,90 & 97,90 & 0,59 & 87,77 & 0,73 & 93,06 \\
\hline $2-6$ & 0,77 & 94,42 & 0,90 & 97,76 & 0,59 & 87,88 & 0,73 & 93,11 \\
\hline $1-6$ & 0,76 & 95,11 & 0,89 & 98,03 & 0,56 & 88,59 & 0,73 & 94,15 \\
\hline
\end{tabular}

${ }^{1}$ Produção de matéria seca no período da seca; ${ }^{2}$ Altura da planta no momento do corte no período da seca; ${ }^{3}$ Tolerância a doenças no período da seca; ${ }^{4}$ Altura de plantas no florescimento no período da seca; ${ }^{5}$ Repetibilidade; ${ }^{6}$ Coeficiente de determinação; e ${ }^{7}$ As avaliações referemse ao conjunto de dados avaliados.

Tabela 7. Estabilização genotípica de experimentos de alfafa, realizados no período das águas do ano de 2004/2005

\begin{tabular}{|c|c|c|c|c|c|c|c|c|}
\hline \multirow{2}{*}{ Avaliações $^{7}$} & \multicolumn{2}{|c|}{ PMSA $^{1}$} & \multicolumn{2}{|c|}{$\mathbf{A P C A}^{2}$} & \multicolumn{2}{|c|}{$\mathbf{T D A}^{3}$} & \multicolumn{2}{|c|}{$\mathbf{A F A}^{4}$} \\
\hline & Rep. $^{5}$ & Det. $(\%)^{6}$ & Rep. $^{5}$ & Det. $(\%)^{6}$ & Rep. $^{5}$ & Det. $(\%)^{6}$ & Rep. $^{5}$ & Det. $(\%)^{6}$ \\
\hline $1-2$ & 0,69 & 81,59 & 0,46 & 63,14 & 0,12 & 21,17 & 0,17 & 29,43 \\
\hline $2-3$ & 0,49 & 66,17 & 0,52 & 68,04 & 0,42 & 58,91 & 0,19 & 32,60 \\
\hline $3-4$ & 0,70 & 82,21 & 0,86 & 92,43 & 0,50 & 66,49 & 0,64 & 78,18 \\
\hline $4-5$ & 0,83 & 90,49 & 0,91 & 95,42 & 0,57 & 72,78 & 0,47 & 64,21 \\
\hline $1-3$ & 0,57 & 80,14 & 0,58 & 80,73 & 0,29 & 55,01 & 0,24 & 48,23 \\
\hline $2-4$ & 0,55 & 78,70 & 0,62 & 82,91 & 0,40 & 66,69 & 0,37 & 63,80 \\
\hline $3-5$ & 0,74 & 89,61 & 0,87 & 95,06 & 0,42 & 68,13 & 0,53 & 77,23 \\
\hline $1-4$ & 0,57 & 83,98 & 0,64 & 87,86 & 0,30 & 63,10 & 0,31 & 63,91 \\
\hline $2-5$ & 0,63 & 87,03 & 0,69 & 89,76 & 0,34 & 66,95 & 0,40 & 73,09 \\
\hline $1-5$ & 0,61 & 88,69 & 0,69 & 91,68 & 0,27 & 64,44 & 0,36 & 73,90 \\
\hline
\end{tabular}

${ }^{1}$ Produção de matéria seca no período das águas; ${ }^{2}$ Altura da planta no momento do corte no período das águas; ${ }^{3}$ Tolerância a doenças no período das águas; ${ }^{4}$ Altura de plantas no florescimento no período das águas; ${ }^{5}$ Repetibilidade; ${ }^{6}$ Coeficiente de determinação; $\mathrm{e}^{7}$ As avaliações referem-se ao conjunto de dados avaliados.

Rev. Ceres, Viçosa, v. 57, n.5, p. 642-647, set/out, 2010 


\section{CONCLUSÕES}

As variáveis PMS e APC, no período das águas, apresentaram maiores estimativas do coeficiente de repetibilidade do que as TD e AF antes de realizar a estabilização genotípica.

A realização da estabilização genotípica permitiu confiabilidade acima de $90 \%$ na avaliação da PMS e APC e entre 70 e $80 \%$ para TD e AF com três cortes em cada época de análise.

\section{REFERENCIAS}

Botrel MA, Ferreira R de P, Alvim MJ \& Xavier DF (2001) Cultivares de alfafa em área de influência da Mata Atlântica no Estado de Minas Gerais. Pesquisa Agropecuária Brasileira, 36:1437-1442.

Cruz CD (2006) Programa GENES: Estatística experimental e matrizes. $1^{\text {a }}$ ed. Viçosa, Editora UFV. 285p.

Cruz CD, Regazzi AJ \& Carneiro PCS (2004) Modelos biométricos aplicados ao melhoramento genético. $3^{\text {a }}$ ed. Viçosa, Editora UFV. 480p.

Ferreira R de P \& Pereira AV (2005) Melhoramento de forrageiras. In: Borém A (Ed.) Melhoramento de espécies cultivadas. Viçosa, Editora UFV. p.781-812.

Ferreira R de P, Rassini JB, Rodrigues AA, Freitas AR, Camargo AC \& Mendonça FC (2008) Cultivo e utilização de alfafa nos trópicos. São Carlos, Editora da Embrapa Pecuária Sudeste. 469p.

Fontes PCR, Martins CE, Cóser AC \& Vilela D (1993) Produção e níveis de nutrientes em alfafa (Medicago sativa L.) no primeiro ano de cultivo na Zona da Mata de Minas Gerais. Revista da Sociedade Brasileira de Zootecnia, 22:205-211.

Guines F, Julier B, Ecalle C \& Huyghe C (2002) Genetic control of quality traits of lucerne (Medicago sativa L.). Australian Journal of Agricultural Research, 53:401-407.

Julier B, Huyghe C \& Ecale C (2000) Within and among cultivar genetic variation in alfafa: Forage quality, morphology in a yield. Crop Science, 40:365-369.

Katepa-Mupondwa FM, Christie BR \& Michaels TE (2002) An improved breedings strategy for autotetraploidy alfafa (Medicago sativa L.). Euphytica, 123:139-146.

Vilela D (1994) Potencial do pasto de alfafa (Medicago sativa L.) para produção de leite. In: Botrel MA, Alvim MJ \& Passos LP (Eds.) Workshop sobre o potencial forrageiro de alfafa (Medicago sativa L.) nos trópicos. Universidade Federal de Viçosa. p.171-185. 